\title{
O 25 DE ABRIL DE 1974 \\ Memória da Revolução e Revolução da Memória
}

\author{
Maria Manuela Cruzeiro \\ Universidade de Coimbra, Portugal
}

\begin{abstract}
Resumo: Este artigo aborda as interconexões entre a memória colectiva e a memória individual de quem viveu a experiência revolucionária do 25 de Abril de 1974 em Portugal. Discute-se a dimensão afectiva e emocional das memórias e o seu carácter fragmentado e parcelar. Seguidamente aborda-se o papel do comemorativismo e denuncia-se a desmemória que tem caracterizado as comemorações da Revolução dos Cravos em Portugal.
\end{abstract}

Palavras-chave: 25 de Abril de 1974; memória; revolução.

Bem-aventurados os que vivem a história, a eles pertence o reino dos céus que os cobrem. Muito mais do que aos que fazem a história. Esses estão condenados ao limbo onde retocam até ao infinito as imperfeições invencíveis da natureza humana. Nada pode comparar-se à emoção de um povo que recupera a liberdade. Ele ultrapassa, como vaga alterosa, todos os projectos razoáveis forjados em seu nome!

Álvaro Guerra, Café 25 de Abril (1987, p. 35)

1. Ninguém melhor do que um escritor para traduzir a situação de quem, passados 40 anos, revisita um acontecimento que continua a ser fonte de emoções e reacções apaixonadas e tema das mais variadas investigações e estudos. Como acontecimento global, que rasga de alto a baixo determinada estrutura social, subvertendo valores, crenças, comportamentos e modelos políticos, culturais ou éticos, a revolução sendo história, é muito mais do que isso. Não podendo prescindir dos contributos dos historiadores, eles parecem-nos sempre escassos e limitados para traduzir o pulsar interno dos acontecimentos, a intensidade com que foram vividos, a sua natureza única e irrepetível.

A verdade é que não podemos pedir à história o que ela não pode dar. Podemos saber tudo sobre as circunstâncias históricas que possibilitaram a eclosão de uma revolução num país dos confins da Europa, onde ninguém acreditava nessa possibilidade. Mas, como sabemos, a verdade não se reduz àquilo que pode ser explicado e verificado por qualquer sequência lógico-causal. A realidade é diferente da totalidade dos factos 
verificados. Há uma dimensão humana dos acontecimentos, uma significação ética e política dessas experiências que a memória histórica está longe de poder alcançar.

Radica aqui a vasta e complexa problemática da memória e da clássica divisão entre memória individual e memória colectiva. A memória individual de quem viveu a experiência revolucionária caracteriza-se por uma intensa dimensão afectiva e emocional, situando-se numa linha de proximidade quase 'osmótica' com a realidade vista pelo seu lado interno, mais íntimo e directo, mas necessariamente mais fragmentado e parcelar. Alheia às grandes preocupações interpretativas e integradoras, a memória individual obedece sobretudo à necessidade vital de preservar e transmitir experiências variadas e únicas, projectando luz sobre a diversidade e complexidade daquilo que tantas vezes nos é mostrado como uma sucessão de factos de sentido único e inquestionável. Neste caso, o comum mecanismo de lembrar/esquecer alimenta uma corrente necessária à sobrevivência de diferentes grupos e indivíduos e à reestruturação de identidades, de intencionalidades e de valores que, mesmo não sendo dominantes, não podem ser excluídos, porque são traços definidores do rosto deste país. Ou seja, descobrir como nasceram e porque morreram tantos e tão ambiciosos projectos de mudança, nesse tempo curto mas exaltante em que o futuro deste país estava nas nossas mãos, é perceber que, apesar de vencidos, tais projectos não são, por isso, menos importantes para o conhecimento do que fomos e, consequentemente, do que poderemos vir a ser. Prescindir desse património é como apagar dos retratos de família alguns rostos mais incómodos. Ao contrário, dar-lhes o seu lugar, ou resgatar as suas vozes, é reconhecer a memória individual como um poderoso filão simbólico e compreensivo para diferentes grupos e indivíduos. Ou seja, como fonte de práticas sociais, culturais e políticas mobilizadoras e marca identitária de uma sociedade em busca constante das suas próprias memórias e projectos.

Quanto à memória colectiva, e de acordo com a já clássica definição de Maurice Halbwachs (1950), ela é normativa, simbólica e fora do tempo.

Antes de mais, porque o referido mecanismo lembrar/esquecer se constitui neste caso não como condição natural da memória (para lembrar é preciso esquecer), mas como eixo vital de permissão discursiva, de verdade social, e de controlo informativo. Neutralizando as contradições históricas e os conflitos sociais, a memória colectiva selecciona do passado o que considera importante para o indivíduo ou para a colectividade e organiza e orienta todo esse material segundo um sistema de valores inquestionável. 
Daí, a segunda característica: simbólica. Os acontecimentos escolhidos são idealizados, quando não mesmo sacralizados, e os valores e referências sobrepõem-se à procura da verdade do acontecido. Ligando directamente o passado e o presente, aponta-se uma visão de futuro, neutralizando e pulverizando o processo histórico. Finalmente, a memória colectiva situa-se fora do tempo. Aprisiona as especificidades emocionais e reduz a complexidade das experiências, estabelecendo um deslocamento temporal no vivido, como se fosse recoberta por uma dimensão vazia de tempo. O que significa que se opera um fenómeno de desnaturalização que se traduz na redução do sentido da memória como algo suspenso no tempo.Esta prática medieval, que coloca o cemitério no centro eclesial da aldeia, exatamente como a morte está no centro da vida, traduz uma rutura com as antigas tradições romanas. Tais tradições exilavam os cadáveres, que eram tabu, para longe do coração da cidade, para os arredores afastados, ou então para túmulos que ladeavam as estradas, fora da cidade. O corpo do cavaleiro, todavia, depois de algumas dezenas de anos na sepultura, debaixo do soalho do santuário, será lançado na vala comum... a sua alma andará então errante por uns tempos ou voltará para junto dos vivos. Mas não tardará a regressar ao repouso, em que permanecerá até ao fim dos tempos, de onde apenas despertará, "ao som de trombetas”, no dia do juízo final.

2. Aplicando este quadro teórico, necessariamente esquemático, ao caso concreto da Revolução Portuguesa, parece evidente o desequilíbrio: a memória colectiva domina, obscurece e quase apaga a memória individual, pois as condições de sobrevivência de cada uma delas não podem ser mais desiguais.

Percorrendo sumariamente as várias formas de memória colectiva, é fácil concluir que, apesar das óbvias diferenças entre si, um mesmo princípio unificador preside à sua organização, impondo uma leitura hegemónica dos acontecimentos históricos englobados na designação genérica de revolução. Deixando por agora de parte dois casos especiais de memória colectiva (o comemorativismo e a comunicação social), verificamos que, tanto ao nível da divulgação histórica, como nos domínios da produção científica, dos centros de investigação ou dos programas escolares, as leituras propostas obedecem àquilo que Rui Bebiano chama com propriedade operação de desmemória:

Desmemoriados, reconhecemos então como passado, apenas o que nos é transmitido por intermédio de uma informação criteriosamente seleccionada, já não tanto aquilo que nos contam ou que, sozinhos ou acompanhados, somos capazes de recuperar (Cruzeiro \& Bebiano, 2006, p.9). 
Em termos gerais, essa leitura hegemónica veicula versões no mínimo simplistas e redutoras, onde não cabe uma infinidade de memórias individuais discordantes. Exemplos dessas versões: O país democratizou-se automaticamente, com uma revolução sem sangue, ultra-consensual, que não teve uma única reacção negativa, e que depois de um breve período de alguma confusão da responsabilidade de perigosos esquerdistas, entrou no eixos da normalidade de uma democracia parlamentar, ocidental, caminho único e óbvio, rumo ao progresso e à paz social.

A tendência dominante, quase exclusiva, do poder em Portugal, após o grande susto do PREC - Processo Revolucionário em Curso (trauma silencioso de que pouco ou nada se fala) tem sido a da naturalização da democracia representativa, ou seja da produção da ideia de que

a democracia representativa é indiscutível, que qualquer outro tipo de regime mais progressivo pertence à categoria das ideias utópicas e inacessíveis, reduzindo o criticismo popular ao interior do regime, sem jamais discutir o regime em si (Silva, 2002, p.146).

Contrapõe-se assim revolução - diabolizada ou minimizada como crise passageira ou epifenómeno insignificante - e democracia, numa operação puramente ideológica, legitimando um caminho para a sociedade portuguesa que passa pela liquidação de uma parte essencial do património de conquistas políticas, sociais e culturais, iniciadas em 1974 e consagradas constitucionalmente em 1976.

Para saber do que falamos, basta recordar o polémico episódio em torno das Comemorações dos 30 anos do 25 de Abril, que a comissão oficial nomeada para o efeito entendeu submeter ao tema Abril é Evolução. Ao omitir uma simples letra, apaga-se o passado revolucionário, celebrando o presente neo-conservador e neoliberal, numa complexa operação de marketing, situada algures entre a amnésia e a mentira. Amnésia, porque ignora que a democracia nasceu justamente de uma revolução e não de um qualquer continuismo liberalizante. Que ela não foi outorgada, mas conquistada por um corte brutal e violento com o passado da ditadura. Mentira, porque o tão celebrado progresso ou evolução, se fez (se vem fazendo) segundo um modelo que não prolonga nem aprofunda os valores de Abril, antes é feito ao arrepio das suas promessas e esperanças. Em termos psicanalíticos, amnésia e mentira parecem ser afinal os dois polos que marcam a forma como o regime democrático lida com esse trauma silencioso que é o 25 de Abril. Mesmo que o comemore, ou justamente porque o comemora... para mais facilmente o esquecer! 
3. O fenómeno do comemorativismo, apesar de pertencer ao vasto e complexo campo da memória colectiva, acrescenta às características comuns outras de tal importância, que frequentemente o autonomizam em relação a manifestações da mesma constelação. Com efeito, para além das características já apontadas para a memória colectiva em geral, na comemoração surgem outras que são, afinal, os seus mecanismos reguladores. Em primeiro lugar, o mecanismo do recalcamento e exaltação. Na comemoração há como que uma organização do esquecimento (melhor: da desmemória), conta-se uma história ficcionada, censurada de acordo com determinados pressupostos ideológicos e políticos. Em segundo lugar, o mecanismo da unificação e síntese. Neutralizando as contradições históricas, a comemoração unifica, organiza e hierarquiza várias memórias em concorrência, que podem unir-se ou excluir-se. Tende-se, assim, a promover o consenso com base numa narrativa coesa, dominante, ou mesmo exclusiva. Compreende-se que comemorar qualquer evento do passado vise gerar os mais amplos consensos, embora o unanimismo total seja mais uma construção ideológico-política, uma imagem construída, nunca uma imagem real de determinada sociedade. Em resumo, comemora-se sempre o crédito, nunca o débito, comemoram-se sempre conquistas e nunca derrotas, comemora-se sempre o presente, ou o que do passado interessa ao presente. Nenhuma comemoração é inocente.

Apesar de brevemente expostos, os traços essenciais do fenómeno do comemorativismo são facilmente detectáveis naquilo que entre nós tem sido a comemoração da revolução. Tudo parece ter vindo a cumprir-se de acordo com a norma. Ou quase tudo. Porque há um elemento não estrutural, mas conjuntural, que altera significativamente a situação portuguesa: a baixa intensidade com que a nossa sociedade vem cumprindo o ritual da comemoração.

A ideia muito difundida de que não há melhor comemoração para a democracia do que a sua vivência diária, se por um lado é uma clara e inequívoca demonstração da superioridade desse regime político sobre qualquer outro, por outro lado, corre o risco de conduzir a uma banalização e até a um esvaziamento do conteúdo da cidadania, no sentido do aprofundamento dessa mesma democracia que, mais do que construção e conquista diária, aparece como dado natural imutável e irreversível. Ora, nada é tão contrário à experiência histórica, que a todo o momento nos prova o difícil equilíbrio em que vivem as sociedades democráticas: a sua força é também a sua fraqueza. Como afirmou José Saramago, nos já longínquos 20 anos da revolução: a democracia, sendo o melhor de todos os sistemas, concilia-se demasiado facilmente com o paradoxo de nela, por ela, e com ela, se poder fazer democraticamente aquilo que, de democrático nada tem. 
Ou seja: não discriminando, à partida, os cidadãos por convicções políticas, religiosas, ou outras, a democracia trata de igual forma democratas e não democratas. Acreditando no poder da persuasão, do diálogo e do compromisso, recusa meios violentos de se impor e até de se celebrar, como acontece com os regimes ditatoriais, cujo segredo reside, justamente, na sábia gestão dos diferentes graus de violência: ora explícita, ora difusa e subtil, como acontece na utilização do indispensável capital simbólico a que todos os regimes recorrem como forma complementar de legitimação. Ora é esse capital simbólico que também a democracia não pode dispensar. Sobretudo se se trata de sociedades como a nossa de muito recente e frágil tradição democrática.

Contudo, a democracia nascida em Abril não pôde ou não soube encontrar forma adequada de se comemorar. Ao longo dos anos a celebração da data arrasta-se, oscilando entre momentos de baixa intensidade, traduzidos num consensualismo anódino e pacificador, e momentos de alta intensidade em claro paralelismo com as grandes datas de um passado glorioso de séculos. Em ambos, por razões que tentarei expor, Abril se encontra ausente, ou no mínimo, bastante transfigurado. No primeiro caso, incluo os chamados festejos populares, as mais das vezes de iniciativa local, que, com louváveis excepções, se cumprem repetidamente, sem qualquer inovação ou criatividade, apenas porque se trata de um feriado como qualquer outro. Estamos perante uma versão mínima, quase residual: 25 de Abril, dia da Liberdade! De pouco tem servido o indisfarçável desconforto daqueles que se sentem mais participantes em exéquias do que em comemorações. A comparação do feriado (dia da Liberdade) com outros já muito amarelecidos pelo tempo como o 5 de Outubro de 1910 (implantação da República) começou cedo e é cada vez mais uma constante a ponto de, com objectivos diferentes, se chegar a defender a extinção pura e simples de tais iniciativas, pela enorme distância a que ficam do verdadeiro espírito de Abril. Na verdade, como disse, o que elas veiculam é uma pálida imagem do 25 de Abril, totalmente expurgada da sua natureza revolucionária e, portanto, de todo e qualquer sinal de conflito e de ruptura. $\mathrm{O}$ conflito, a existir, terá que ser contido no lugar que lhe destina a normalidade de uma democracia representativa: o parlamento. Assim, os partidos políticos com representação parlamentar protagonizam a outra vertente das comemorações de baixa intensidade. Apesar da forma diferente com que cada partido lida com a memória da revolução, o certo é que essas diferenças retóricas não chegam para alterar o figurino engravatado e solene com que o 25 de Abril visita uma vez por ano a chamada casa do povo. Sem entusiasmo, sem mobilização das massas, cada vez mais afastadas dos seus representantes. Um enorme fosso se foi cavando entre estas duas formas de comemorar Abril: a dos discursos sem povo, e a do povo sem discursos. 
Mas há também as comemorações de alta intensidade, que pretendem colocar Abril em lugar especial na galeria das glórias nacionais, como momento só comparável ao que de melhor conseguimos no passado. Mas também aqui se descaracteriza e dilui a verdade da revolução, através de uma espécie de reciclagem de velhos símbolos e de uma velha mitologia do antigo Portugal pré-Abril. Foi assim com a Expo 98, com a mobilização nacional por Timor, com o Campeonato Europeu de Futebol de 2004. Acontecimentos tão diferentes entre si, que só uma imensa operação de mistificação os pode unir. Como se, de repente, num súbito assomo de brio e orgulho nacionais, acordássemos de um estado geral de apatia e indiferença, para dar uma nova lição ao mundo. Como se tudo se resolvesse com milagrosos reforços de orgulho e auto-estima nacional, quando não de desorbitada euforia identitária. O resultado só pode ser um encadeado fatal de equívocos. O principal dos quais é iludir a trágica ausência de um verdadeiro projecto nacional, com uma tão frágil quanto inconsistente galeria de desgarradas propostas, nascidas mais do universo do marketing do que da autêntica realidade nacional. A memória reconfigura-se, assim, através de uma discutível selecção de imagens e símbolos identitários, valorizados apenas em função do seu potencial mobilizador na conjuntura social ou política do momento. Normalmente, esses símbolos e imagens constituem uma espécie de catálogo onde se escolhe o que melhor se adequa a promover uma ideia de Portugal e dos portugueses que pouco ou nada se distingue de um produto comercial. É a marca Portugal de que nos fala essa nova geração de descobridores e visionários, que mais não são do que criativos saídos de empresas de sucesso, agora chamados ao desafio maior de arrastar para esse sucesso a grande empresa nacional. Injecta-se assim auto-estima, orgulho nacional e patriotismo através de acontecimentos que, chamem-se o que se chamarem, mais não são do que campanhas publicitárias públicas ou privadas, servidas pelos ícones que estão na moda nas várias áreas de actividade. Os heróis desportivos são, obviamente, os mais exaltados: José Mourinho, o Special One, Cristiano Ronaldo, ou mais recentemente Eusébio. Mas não são exclusivos. Também Saramago, Paula Rego, Manuel de Oliveira, Siza Vieira, ou a incontornável Joana Vasconcelos são usados (por vezes de forma abusiva) nessa estratégia de marketing e publicidade, ao mesmo nível do vinho do Porto ou do Mateus Rosé, do fado de Lisboa ou dos pastéis de nata, do computador Magalhães, da gastronomia ou das praias do Algarve. Percebe-se que, nesta pobre paisagem, nenhum destes símbolos sobrevive para lá do prazo de validade de um gabinete de estudos ou de uma qualquer comissão (é já proverbial a máxima de que em Portugal, quando surge um problema, cria-se uma comissão!) pois nenhum tem a natureza e o poder catalisador, transformador e futurante de um verdadeiro desígnio. 
4. Na ausência de uma grande causa mobilizadora nacional que seria, por exemplo, o combate pela liberdade contra a ditadura fascista, já que o valor da liberdade parecer ser o único denominador comum para o 25 de Abril (daí o dia da Liberdade), a nova democracia parece preencher esse vazio com um outro combate, que é ao mesmo tempo a sua certidão de nascimento e o seu manual de sobrevivência: o combate contra a memória de 1974/76, obsessão e trauma da nova classe política.

A política portuguesa tem sido um mero exorcismo destinado a libertar-nos dos demónios e das maldições que nos possuíram nesses anos descabelados e os sacrifícios que regularmente nos são pedidos tomam o ar de expiação das terríveis culpas que nos são imputadas por termos posto este país no caos e na anarquia' (Pereira, 1983, p.49).

Neste contexto, percebe-se como a comemoração de Abril ao longo dos anos mais não tem sido do que a auto-comemoração de uma 'normalidade democrática' reduzida à auto-proclamação das virtudes do jogo partidário. De partidos que, por sua vez, mais não são do que meras agências de colocação. E percebe-se como este programa mínimo (por mais e mais variadas que sejam as iniciativas em que se desdobre) não chegue para alimentar e mobilizar energias colectivas. A comemoração de Abril por este regime será sempre uma comemoração ressentida e complexada, uma comemoração mais pela negativa do que pela positiva.

Questões de memória, pois. Mas por tudo isto, talvez hoje mais do que nunca, seja necessário falar do 25 de Abril. Em primeiro lugar, para lembrar aos actuais governantes que o país não começou no dia em que eles próprios nasceram para o mundo. Que Portugal é habitado por um povo que em 25 de Abril de 1974 protagonizou um acontecimento histórico, ao nível dos maiores da sua longa história, e que a memória desses dias é um capital simbólico e uma reserva de auto-confiança e autoestima mais valiosas do que qualquer sucesso na actual batalha da economia.

José Gil, um dos nossos mais ilustres e lúcidos pensadores, traçou num livro justamente intitulado Portugal, Hoje - O Medo de Existir, um diagnóstico implacável. Considera ele que Portugal é o país por excelência da não inscrição. O país onde nada acontece que marque o real, que o transforme, que o abra. Um país sem passado nem futuro. Em que só o presente pontual existe. A transferência de regras morais e de conduta - honradez, honestidade, dignidade, carácter - da esfera privada para a esfera pública não se faz. Os políticos são avaliados por outros parâmetros: ambição, combatividade, sobrevivência. $\mathrm{E}$ as consequências são evidentes: 
O sentimento da responsabilidade por uma comunidade, por um país, parece ter desaparecido. Em política esse tipo de transferência de regras morais de conduta para a esfera governativa pode ser extremamente perigoso. A resignação leva à impotência, à passividade, à inércia e ao imobilismo (Gil, 2004, p.14).

Esta não inscrição significa que nada acontece na história, na existência individual, na vida cultural. Nada nos toca e marca verdadeiramente. E, portanto, vivemos de certa maneira tateando no escuro, sem planos, sem diagnósticos, sem planos. No limite, como afirma Boaventura de Sousa Santos:

as coisas não acontecem, acontecem-nos! A todo o momento somos surpreendidos e perguntamos atónitos: como foi possível? Perguntamos como foi possível o 25 de Abril, mas perguntamos também, como foi possível chegarmos a isto. (Santos, 2003, s.p.).

De algum modo nem merecemos o que nos acontece de bom nem o que nos acontece de mau, porque vivemos em constante desfocagem de expectativas, tanto positivas, como negativas. Isto faz-nos bons do improviso, mas sujeita a tão falada auto-estima a oscilações vertiginosas. Ora somos os melhores, ora somos os piores.

Por isso, regressar hoje ao 25 de Abril tem de ser uma inversão nessa lógica bipolar e redutora tão típica do nosso comportamento colectivo. Tal só se fará se encararmos esse tempo de força, de rebeldia e de criatividade na sua dupla dimensão de memória e de projecto. Que é o mesmo que perguntar de onde vimos (memória) e para onde vamos (projecto). E então, perguntar de onde vem e para onde vai a democracia que aí temos hoje é falar de revolução com todas as letras. Porque foi dela que nasceu a democracia. E perguntar para onde vai, é justamente perguntar por projectos e valores que não se coadunam com a pura gestão de um presente a prazo.

Hoje, 40 anos passados, e citando Lídia Jorge, os ventos da história coroam

todos aqueles que no dia 25 de Abril de 1974 ficaram atrás das portas à espera que a barafunda dos cravos passasse.(...) Os peitos onde nenhum cravo vermelho ou branco alguma vez foi posto são hoje os senhores de Portugal e respiram em nome de todos nós (Jorge, 2014, s.p).

Mas não esquecemos também as sementes de futuro plantadas nessas jornadas laboriosas e festivas, em que caminhámos juntos levados por sonhos mais poderosos do que cada um de nós. Uma das mais puras vozes de Abril, que levou a poesia para rua, disse-o assim: 
Como casa limpa

Como chão varrido

Como porta aberta.

Como puro início

Como tempo novo

Sem mancha nem vício

Como a voz do mar

Interior de um povo

Como página em branco

Onde o poema emerge

Como arquitectura

Do homem que ergue

Sua habitação.

(Andresen, 1977)

\section{Referências bibliográficas}

Andresen, S. (1977). Revolução. In O nome das Coisas. Lisboa: Moraes Editores,

Halbwachs, M. (1950/1997). La mémoire collective. Paris: Albin Michel.

Cruzeiro, M. M. \& Bebiano, R. (2006) Anos Inquietos - Vozes do Movimento Estudantil em Coimbra (1961-1974). Porto: Edições Afrontamento.

Gil, J. (2004) Portugal, Hoje - o Medo de Existir. Lisboa: Relógio d’Água.

Guerra, A. (1987) Café 25 de Abril. Edições D. Quixote.

Jorge, L. (2014) Lembrar o momento perfeito. Jornal de Letras, 16 a 29 de Abril de 2014. Obtido em 25 de Julho de 2014 em: http://visao.sapo.pt/lembrar-o-momentoperfeito $=\mathfrak{f} 777363$

Pereira, J. M. (1983). No Reino dos Falsos Avestruzes. Lisboa: Regra do Jogo.

Santos, B. S. (2003) Bloqueio em Movimento, revista Visão, 24/4/2003.

Silva, T. (2002). Pais de Abril, Filhos de Novembro - Memória do 25 de Abril. Lisboa: Edições Dinossauro.

Maria Manuela Cruzeiro é atualmente investigadora do CES (Centro de Estudos Sociais da U. de Coimbra) onde integra o Núcleo de Estudos sobre Humanidades, Migrações e Estudos para a Paz.

manuelacruzeiro@ces.uc.pt 